\title{
OKROGLA MIZA »(BLIŽNJA) SREČANJA OBLIKOVALCEV JEZIKOVNE POLITIKE«
}

Ina FERBEŽAR, Igor CETINA, Alojz IHAN, Marko STABEJ, Lana ZDRAVKOVIĆ in Tina ZUPANČIČ

Ferbežar, I. et al. (2020): Okrogla miza »(Bližnja) srečanja oblikovalcev jezikovne politike«. Slovenščina 2.o, 8(1): 92-112.

DOI: https://doi.org/10.4312/slo2.0.2020.1.92-112

V Ljubljani sta med 6. in 8. 11. 2019 potekala 54. srečanje in javni posvet združenja ALTE $^{1}$ (Association of Language Testers in Europe). Srečanje na temo Enojezično testiranje v večjezični resničnosti? Jezikovne ideologije in njihov vpliv na jezikovno testiranje sta organizirala Univerza v Ljubljani, Filozofska fakulteta in njen Center za slovenščino kot drugi in tuji jezik pri Oddelku za slovenistiko. V tem okviru je 8. 11. 2019 potekala okrogla miza (Bližnja) srečanja oblikovalcev jezikovne politike, na kateri so sodelovali Igor Cetina z Ministrstva za notranje zadeve RS, prof. dr. Alojz Ihan z Medicinske fakultete Univerze v Ljubljani, prof. dr. Marko Stabej s Filozofske fakultete Univerze v Ljubljani, dr. Lana Zdravković z ljubljanskega Mirovnega inštitutu in Tina Zupančič iz podjetja Revoz.

Okroglo mizo je moderirala dr. Ina Ferbežar s Centra za slovenščino kot drugi in tuji jezik Filozofske fakultete ljubljanske univerze. Pri zapisu so bile izjave za namene lažjega branja skladenjsko prilagojene značilnostim pisnega jezika, vendar po principu minimalne intervencije.

Ina Ferbežar: Najprej bi se rada zahvalila svojim gostom. Lepo pozdravljeni. Zelo redko se srečamo oblikovalci jezikovne politike, takšni in drugačni odločevalci. Danes je naš namen, da se z mojimi sogovorci, ki prihajajo z zelo različnih področij, pogovarjamo o zapletenem razmerju med potrebo po

1 https://www.alte.org/ 
priseljevanju (recimo zaradi pomanjkanja delavcev na nekaterih področjih pri nas, zlasti v zdravstvu trenutno in turizmu), med dejanskimi sporazumevalnimi potrebami priseljencev, med pričakovanji jezikovne skupnosti glede njihovega znanja slovenščine in zahtevami države po tem znanju. In seveda na koncu o jezikovnih pravicah in dolžnostih vseh partnerjev v komunikaciji.

Moji gostje so - bom začela na svoji levi strani - doktorica Lana Zdravković, filozofinja, strokovnjakinja za migracije pri Mirovnem inštitutu in aktivistka na področju človekovih pravic. Za nas posebej zanimiva tudi zato, ker ima sama migrantsko preteklost oziroma migrantsko ozadje. Profesor Marko Stabej, nekateri ste ga danes dopoldne že slišali. Redni profesor za slovenski jezik na Filozofski fakulteti v Ljubljani in strokovnjak za jezikovno politiko. Gospod Igor Cetina je višji svetovalec pri Ministrstvu za notranje zadeve. Skrbnik projektov, namenjenih pomoči pri vključevanju migrantov v slovensko družbo. Profesor Alojz Ihan, zdravnik, redni profesor mikrobiologije in imunologije na medicinski fakulteti naše univerze ${ }^{2}$ in predvsem tudi - kar je za nas še posebej zanimivo - tudi zelo priznan književnik, pesnik in esejist. Na koncu, na moji skrajni desni, Tina Zupančič, vodja službe za izobraževanje pri družbi Revoz (eno od podjetij v sklopu Renaulta), ki bo predstavila pogled delodajalca.

Hvala lepa, da ste prišli.

Jaz sem si tole zamislila bolj kot neformalni pogovor, čeprav so vsi moji gostje že dobili vsaj približna vprašanja vnaprej. Ampak domnevam, da bomo improvizirali. Odločitev, morda povem še to, zakaj v slovenščini. Promoviramo večjezičnost. Danes in te dni smo slišali v glavnem angleščino. To je en razlog. Drugi razlog, mogoče za nas, ki smo predstavniki univerze, še bolj pomemben, tudi simbolni, je ta, da je stoletnica ljubljanske univerze, univerze, ki ima učni jezik slovenski. Pred sto leti je bilo prvo predavanje v slovenščini o slovenskem jeziku. In tretji razlog: vsi smo govorci slovenščine. Bilo bi mogoče nekoliko neobičajno, da bi med sabo govorili angleško. Tako da, hvala za razumevanje.

Mogoče bi začela s profesorjem Ihanom. Pri zdravnikih gre za odločanje o življenju in smrti. Mogoče malo okoliščin za začetek. Trenutno imamo v Sloveniji zelo veliko pomanjkanje zdravnikov. Verjamem, da je tako marsikje, tudi v

2 Univerze v Ljubljani 
drugih državah Evrope. To se je že zgodilo pred leti. Takrat pred leti je bil problem slovenščina. Takrat je minister rekel, da je slovenščina ozko grlo in je znižal raven znanja za zdravnike, da o tem pač odločijo delodajalci. Večina zdravnikov je takrat šla delat izpit na ravni A2. Tak je bil zakon. No, leta sedemnajst pa se je zakon spremenil. Od takrat naprej morajo zdravniki, če želijo delati v Sloveniji, opravljati izpit na ravni C1.

Profesor Ihan je strokovnjak, je sam delodajalec, zelo dobro pozna zadevo, dober pregled ima nad situacijo. Zato vas prosim, če mogoče malo predstavite vse skupaj. Kakšni so tokratni ukrepi, od kod bo Slovenija dobila zdravnike, kako bomo z njihovo slovenščino? Če lahko na kratko predstavite malo situacijo na tem področju.

Alojz Ihan: Ja. Kot ste omenili, pojav pomanjkanja zdravnikov je evropski, tudi svetovni, ampak vsekakor je to evropski pojav. Primarno je nastal zaradi tega, ker še pred desetimi, petnajstimi leti nismo niti slutili, kako zahtevni bodo postali pacienti glede na vso tehnologijo, ki je omogočena. Se pravi še dvajset let nazaj ni bilo običajno, da si vsak človek zamenja očesne leče, da si vsak človek slej ko prej zamenja kolena, kolke [smeh]. Ko je človek dobil raka, je bilo pet let že kar uspeh. Danes ima pravzaprav večina ljudi, ki dobi raka, pred sabo petnajst, dvajset let zelo kompleksnih posegov. Ne umrejo. Tudi avtoimunske bolezni zahtevajo ogromno tehnologije. Zaradi tega je po celi Evropi veliko pomanjkanje zdravnikov. V Evropi opažamo migracije zdravnikov z vzhoda, migracije zdravnikov od tam, kjer je investicija, kjer je denarja na bolnika manj, v države, kjer je količina denarja na bolnika višja. Obstaja en pas evropskih držav, ki se vleče od Skandinavije preko Nemčije, kjer je potrošnja za zdravstvo na prebivalca nad štiri tisoč evrov. Potem je drugi pas, v katerega sodimo tudi mi, kjer je potrošnja nekako dva do tri tisoč evrov. In je potem tretji pas, kjer je potrošnja nekako pod tisoč petsto evrov letno.

Opažamo migracije: iz tretjega pasu migrirajo zdravniki, medicinske sestre v drugi pas. Zakaj ne v prvega? Zaradi tega, ker je drugi pas kulturno bližji jugovzhodu kot pa prvi pas, se pravi, težje je iti večini sester in zdravnikov npr. iz Srbije ali pa Bolgarije ali pa Bosne neposredno v Skandinavijo. Lažje jim je iti v Slovenijo. Čeprav se tudi to dogaja, ampak ne toliko. Te migracije so dejstvo. Vsi se selijo za eno ali pa dve državi bolj proti severu in pa proti zahodu. V Sloveniji imamo isto: migracije iz Slovenije. Okrog 20 odstotkov 
naših diplomantov želi delati preko meje, v Avstriji, čeprav je pri nas ogromno pomanjkanje zdravnikov. Mi bi takoj potrebovali zdravnike za tri ali pa štiri letnike na vseh medicinskih fakultetah. Najboljši način je, da pridejo k nam iz držav nekdanje Jugoslavije zato, ker smo kulturno dosti blizu. Oni nas še nekako razumejo in mi njih. Tudi zainteresirani so. Kadar delamo poizvedovanje npr. v Srbiji, je ogromno interesa, da bi prišli v Slovenijo. Seveda, uvoziti zdravnike je za državo velik plus, ker ni treba investirati dvesto, tristo tisoč evrov za vse izobraževanje. Zaradi tega si prizadevamo, da bi nekako omogočili uvoz zdravnikov, ampak hkrati mora pa to biti varno.

Če mi zahtevamo, da pride sem zdravnik, ki je že jezikovno popolnoma suveren, potem bomo predpostavljali, da bo zdravnik pustil službo v Beogradu in bil potem tukaj eno leto ali pa dve, živel od zraka in se potem tukaj zaposlil. To ni realno. Zaradi tega želimo narediti nek sistem, in ga že delamo, da jezikovni tečaj ne bi bil tako splošen, da bi bil jezikovni tečaj zdravniški. V okviru fakultete imamo programe komunikacije s pacientom. V teh programih, ki jih imajo naši študentje, sodelujejo igralci. Igralci se naučijo določeno bolezen. Potem pride študent k njemu, ga sprašuje, igralec mu pove vse o tisti bolezni, potem dobi dokumentacijo in mora napisati, kaj je s pacientom, kaj kaže dokumentacija, kako ga bo zdravil, v katere diagnostike ga bo poslal. Te module, te programe že imamo za naše študente. Zato smo rekli: zakaj bi se na jezikovnem izpitu moral človek pogovarjati o plezanju po hribih ali pa o igranju hokeja? Sploh če pride iz Makedonije, se bo zelo težko pogovarjal o hokeju, v Sloveniji pa vsak ve vse o hokeju [smeh]. Zaradi tega se nam je zdelo pretirano, da bi zahtevali od tistih, ki se učijo jezik, da so suvereni na vseh kulturnih področjih, ki so nam v Sloveniji samoumevni, medtem ko prišlekom pa niso samoumevni. Zato se nam je zdelo, da je za zdravnika čisto dovolj, da je suveren v tem modulu, ki sem ga opisal. Se pravi, da dobi igralca, da se mora znati z njim pogovarjati o njegovih težavah, da mora znati potem pregledati dokumentacijo v slovenščini, da mora znati napisati, kako bo potekalo zdravljenje, in da to predoči komisiji, ki bo ocenila, če je na medicinskem področju dovolj suveren, da je varen za pacienta. To bi radi uvedli na zdravniški zbornici. Ne bi nižali nivoja izpita, ampak bi za začetek zahtevali ta zakonsko predpisan nivo izpita v območju komunikacije s pacientom. Sicer je iz številnih jezikovnih študij znano, da je nepopolno obvladovanje jezika v nekaterih strokah 
lahko nevarno. Manj nevarno je npr. v splošni medicini. Če zdravnik svojega pacienta pozna in ta redno hodi $\mathrm{k}$ njemu, ve za njegove bolezni, potem se oba nekako prilagodita v tej komunikaciji. Imeli smo že izkušnje s splošnimi zdravniki, tako kot je kolegica povedala, v tistem obdobju, ko zakon ni zahteval znanja slovenščine. Takrat ljudje niso bilo tako zelo nezadovoljni s splošnimi zdravniki. Rekli so: »Hvala bogu, vsaj zdravnika imamo. Dajmo primerjati s stanjem, ko ga nimamo.« Če nas ta zdravnik pozna in imamo z njim kontinuirana srečanja, nas ta zdravnik toliko razume in mi njega, da ne bo kakšnih velikih težav.

Drugo pa je recimo na urgenci. Na urgenci je vso komunikacijo od pacienta potrebno dobiti v petih, šestih minutah. Potem sledi ukrepanje, ki pa je lahko življenjsko ogrožajoče, če je napačno. Na urgenci pa mora tisti, ki se pogovarja s pacienti, zelo dobro vedeti, kaj pomenijo tudi medvrstični izrazi. Ljudje imamo za to, da smo pijani ali pa da smo zadrogirani ali pa da smo se z nekom stepli, velikokrat zelo različne izraze. Recimo nekdo bo rekel: »Malo je čuden «. To lahko v nekem kraju pomeni, da se je napil, in tisti, ki sprašuje tega pacienta in tega ne ve, lahko naredi hude napake. Lahko nekoga, ki je povedal, da mu je slabo, razume, da se je napil. Pa ne bo vedel, da se je on pravzaprav udaril v glavo in da bi ga moral poslati na slikanje. Na urgenci je 90 odstotkov ljudi, ki so poškodovani, ki morajo samo malo počakati. Problem je pa ujeti tistih 10 odstotkov ljudi, ki jih je treba dati naprej.

Ina Ferbežar: Če lahko samo na kratko povzamem. Vi predlagate za različne specializacije malo različne nivoje znanja in dejansko uporabo jezikovnega profila, to, čemur je nenazadnje namenjen Skupni jezikovni okvir ${ }^{3}$. To je ena zadeva. Mogoče pa tole dopolnitev. Zakaj izpit za zdravnike? Ko je izšel zakon, da morajo zdravniki opravljati izpit na $\mathrm{C}$, so zdravniki prišli in je bil zelo, zelo slab uspeh. Komaj 20 procentov zdravnikov je opravilo ta izpit, ker seveda pridejo in zelo na hitro hočejo na izpit. Kar profesor tudi predlaga, če sem vas prav razumela, je nek specializiran tečaj.

Alojz Ihan: Ja. Idealno bi bilo, da bi se delodajalec zavezal, da bo zdravnik imel eno leto takšnega statusa, da bo s pacienti delal samo pod mentorstvom

3 Skupni evropski jezikovni okvir: učenje, poučevanje, ocenjevanje - SEJO, prevod dokumenta Sveta Evrope o jezikovnem poučevanju nasploh: https://centerslo.si/wpcontent/uploads/2015/10/SEJO-komplet-za-splet.pdf 
in da bi mu v tem času obvezno omogočal in tudi plačeval tečaj, enoletni tečaj slovenskega jezika, v katerem bi bila skupina tečajnikov samo zdravnikov.

Ina Ferbežar: Homogena (skupina).

Alojz Ihan: Samo tisti kandidati za zdravniški izpit naj bi bili skupaj na tečaju, zato da bi vadili predvsem komunikacijo s pacientom, ki jo bodo potem tudi na izpitu imeli. To je nekako želja.

Ina Ferbežar: Hvala lepa. Tukaj smo zdaj pri dostopu do znanja. Seveda, idealno bi bilo, če bi zato poskrbel delodajalec. Kar nekaj dostopa do znanja ponuja država. In bi se tukaj preselili mogoče h gospodu Cetini, ki je predstavnik Ministrstva za notranje zadeve. Moram najprej povedati, da Center za slovenščino ${ }^{4}$ zelo dobro sodeluje z notranjim ministrstvom. Jaz mislim, da nam kolegi iz tujine lahko včasih tudi zavidate, da je tako. Dostikrat nas pokličejo in nas vprašajo za mnenje. Včasih pa tudi ne.

Igor Cetina: In obratno. [smeh]

Ina Ferbežar: In obratno, seveda. Moram seveda povedati okoliščine. Slovenija ponuja dostop do znanja migrantom. Razmeroma pozno smo začeli z brezplačnimi tečaji, in sicer se program imenuje Začetna integracija priseljencev. ${ }^{5}$ To je 180 -urni tečaj, ki se ga udeležujejo državljani tretjih držav. In gospod Cetina je strokovnjak za to. Mogoče za začetek: Kakšni so trendi, kakšno je trenutno stanje, koliko ljudi se uči, se vključuje v te programe začetne integracije?

Igor Cetina: Če dovolite, ne bi se osredotočil samo na program Začetne integracije priseljencev. 18. septembra je minilo deset let, odkar je Ministrstvo za notranje zadeve podpisalo prvo pogodbo za takratni tečaj slovenskega jezika. Začetna integracija priseljencev je program, v katerem se izvaja tečaj od leta 2012 naprej. Mi gledamo na to kot na kontinuiteto izvajanja, ne pa neki hud presek. Jaz imam tukaj par številk in če imate čas in voljo, vam jih lahko malo predstavim. V grobem: številke zajemajo področje od septembra 2009 do 31. oktobra letos ${ }^{6}$. V tem času je z obiskovanjem tečajev, ki jih organiziramo mi,

4 https://centerslo.si/

5 Začetna integracija priseljencev, krajše ZIP.

$6 \quad 2019$ 
začelo 12810 ljudi. Največ jih je v starostni skupini od 26 do 35 let in največ je žensk. Med 12810 je kar 7885 žensk, medtem ko je slabih 5000 moških. Če pogledamo države: tečajniki so prihajali iz preko stotih držav. Iz nekaterih je samo en tečajnik, tako da se bom osredotočil samo na tistih glavnih pet držav, v katerih imamo trimestna števila. Največ jih je, seveda, iz Bosne in Hercegovine, skupaj 6221. Preostale države so tudi v prvi vrsti s področja bivše Jugoslavije. Črna Gora 116, Hrvaška - čeprav Hrvati od leta 2015 niso več upravičeni do teh tečajev - 179, 101 Kitajec, 1240 oseb s Kosova, 770 iz Ruske federacije, 966 iz Severne Makedonije, 1304 iz Srbije ter 577 državljanov iz Ukrajine. To so samo tisti, kjer imamo trimestne številke, vse ostalo so statistično manjše številke. To je nekako to.

Kakšni so trendi v zadnjem obdobju? Niti ne spremljamo toliko po državljanstvih, gledamo bolj celostno sliko. Za tiste, ki vas zanima bolj splošno področje migracij, sem pustil naših nekaj statističnih poročil zunaj in si lahko pogledate.

Ina Ferbežar: Zelo veliko ljudi med temi, ki se udeležujejo teh programov, opravlja izpit iz znanja slovenščine. Ministrstvo za notranje zadeve uporablja izpite iz znanja slovenščine, ki jih izvajamo na Centru za slovenščino. To niso izpiti, ki so narejeni posebej za ta namen. To so splošni izpiti. Tukaj prihaja pri nas malo do kratkega stika, ker recimo ljudje, ki se udeležujejo Začetne integracije priseljencev, 180-urni tečaj, lahko gredo na izpit A2, ki pa je delan za popolnoma druge namene, z drugimi cilji in veliko več ur se predvideva, da prideš do stopnje A2, in sicer od 300 do 450 ur. Moje vprašanje tukaj bi bilo: zakaj ste se odločili za to kombinacijo, če gre za različne cilje, za različno število ur?

Igor Cetina: No, pa smo spet pri komunikaciji. Prvič, ker Center za slovenščino takrat ni obvestil, da bo spremenil svoje izpite, ko je leta 2016 šel na višji nivo.

Ina Ferbežar: Popolnoma enak izpit je ostal.

Igor Cetina: Glavni razlog je sama narava programa Začetna integracija priseljencev. Poleg jezikovnih vsebin ta vsebuje tudi vsebine iz poznavanja slovenske zgodovine, družbe in ustavne ureditve. Ta je bila na začetku mišljena kot ločen program, vendar je bila izredno slabo obiskana, tako da smo ga zdaj združili s tečajem slovenščine. Udeleženci lahko spoznavajo vse vsebine. 
Program predvideva tudi spoznavanje lokalnega okolja, tako da se ljudje lažje vpnejo tudi v lokalno okolje. Priznam, da ne poznam toliko programa, o katerem ste govorili. Se mu nisem toliko posvečal, tako da ne vem, ali tudi ta to vsebuje. Ampak ZIP pač to vsebuje in ni osredotočen izključno na slovenščino.

Ina Ferbežar: Saj zato sprašujem.

Igor Cetina: Če dovolite, nadaljujem. Zdaj bom zelo suhoparno povedal, ker se vsi se zavedamo, da to ni res. Ampak mi gledamo na to, da nekdo dobi državljanstvo, kot na zaključek integracije. To je zelo formalno gledano. In mi pač ponujamo možnost. Brezplačen tečaj kot vstop v to možnost in izpit kot zadnji korak, zato da lahko to oseba izkoristi, zato da lahko pridobi dokument, ki je eden od pogojev za pridobitev državljanstva. Nikjer ne piše, da morajo iti takoj, ko opravijo tečaj, tudi na izpit. Važno je samo, da so 80 procentov prisotni na tečaju.

Ina Ferbežar: Zakaj tako vztrajam pri tem vprašanju. Namreč, malo paradoksalna situacija je nastala: ljudje, ki so prosilci za slovensko državljanstvo, so že dolgo časa v Sloveniji.

Igor Cetina: Vsaj pet let.

Ina Ferbežar: Potem se udeležijo tečaja začetne integracije priseljencev, ki je namenjena res tistim, ki začnejo. Poleg tega pa ta tečaj, ta program, ne predvideva nobenega izpita ravno zato, ker vsebine, kot so ustavna ureditev, poznavanje družbe - tega ne preverjamo, ker o tem lahko govorimo šele na nivoju B2 - to so abstraktne zadeve. To je problem. Zato, malo moram izzivati, saj veste. Bomo nadaljevali to debato. Vsekakor ti ljudje gredo na izpit. Tukaj mogoče nadaljujem pri vas, doktorica Zdravković.

Mimogrede, ko sva se z gospo Zdravković prvič srečali, mi je rekla: »Midve se že poznava. Pri vas sem delala izpit. « Sem rekla: »O, moj bog. A je bilo hudo?« Je rekla: »Ne! Super izkušnja! « Tako da, hvala, Lana, za to »super izkušnjo«.

Moje vprašanje bi bilo, v zvezi s priseljenci, ki morajo na izpit. Vam namreč ni bilo ravno treba, za vas je bila to dobra izkušnja, za večino pa ni. Za večino teh kandidatov, o katerih je pripovedoval gospod Cetina, je to argument moči. Argument moči, ki ga naša država izvaja. In me zanima, od česa je odvisno, ali bo izkušnja bolj negativna ali bolj pozitivna, če se udeležiš izpita? In kako vi kot 
filozofinja gledate na to: a ima izpit tudi moč argumenta, a je vedno samo nek pokazatelj moči, kontrole in tako naprej? Ti dve vprašanji, če lahko odgovorite.

Lana Zdravković: Dejstvo je, da se vsaka nacionalna država vzpostavi, med drugim tudi s homogenizacijo, unifikacijo in kodifikacijo nacionalnega jezika. Vstop v ta jezik predstavlja del nekega širšega pogleda integriranja v družbo. Ti procesi učenja jezika, jezikovnih tečajev so potemtakem del nekega širšega sindroma integracije v neko družbo, ki predpostavlja tudi sprejemanje nekaterih pravil, odgovornosti in tudi poznavanje nekega širšega konteksta države, v katero se preseliš in katere del na nek način postaneš.

Ti vstopi so lahko bolj ali manj boleči, bolj ali manj travmatični. Odvisno seveda od tega, iz kakšnih okoliščin določena oseba prihaja v določeno državo in tudi, nenazadnje, v kakšno situacijo prihaja. Seveda je tukaj zelo pomembno razredno vprašanje oziroma ekonomska situacija osebe, in s kakšno situacijo se sooča, ko pride v to državo. Ali jo že čaka neka služba, kot je prej bilo povedano, neki zdravnik pride, tukaj ga čaka vse. Ali pa pride nekdo kot, agambenovsko povedano, homo sacer, neko golo človeško bitje. To so zdaj begunci, s katerimi se mi soočamo. Danes je ravno eden umrl na meji. Seveda, ne vem, če veste, Slovenija se ponaša z žico na svoji zunanji meji, tako da je to tudi ena lepa pridobitev, ki jo imamo.

Če nekdo pride $\mathrm{v}$ takšnih okoliščinah, ko nima ničesar in ga nič tukaj ne čaka oziroma zelo malo, potem je seveda ta vstop zelo travmatičen. Jaz delam z migranti, z begunci, prosilci za azil. Pri svojem delu se soočam z deljenjem izkušenj z njimi. Tudi iz njihovih pripovedovanj, pa tudi meni se zdi tako zelo logično, da je teh 180 ur, ki je zapovedanih, zelo malo.

Igor Cetina: Ja, ampak mislim, da imajo te osebe ...

Lana Zdravković: Imajo 320 ur potem, ampak ni dovolj, pravijo, tako da je mogoče treba razmisliti o tem. Mi smo delali tudi par projektov na Mirovnem inštitutu, ${ }^{7}$ kjer smo to raziskovali. Ugotavljamo, da to ni dovolj za osebo, ki pride iz nekega totalno drugega jezikovnega področja. Ne bi bilo slabo, da je mogoče teh ur več. Je pa fascinantno potem, ko spoznaš na primer enega Afganistanca ali pa Sirca, ki se je v šestih mesecih naučil slovenščine. To je res 
fascinantno. Jaz sem iz Srbije prišla, iz Beograda, in vem, kako je. Že meni se je bilo težko slovenščine naučiti, pa si mislim, kako je šele enemu, ki je z nekega čisto drugega jezikovnega področja.

Tudi preverjanja znanja seveda predstavljajo neko moč države po eni strani. Po drugi strani pa tudi neki čisto pragmatični korak k temu, da se oseba vključi v neki dominanten jezik, kar je, zelo pragmatično, tudi potrebno. Jaz mislim, da bi bilo potrebnih več ur in bolj sistematično vključevanje v to. Tudi pri svojem delu in pri delu s prijatelji migranti, s katerimi jaz sodelujem, vidim, kako je tudi njim pomembno, da se slovenščine čim prej naučijo, ker je od tega odvisno tudi njihovo vključevanje na trg dela. Oni so izobraženi za določene poklice, ampak se ne morejo vključiti, dokler slovenščine ne znajo dobro, tako da je to absolutno zelo pomembna stvar.

Verjamem pa, da ti jezikovni izpiti, na splošno neka preverjanja znanja travmatizirani osebi in osebi iz nekega čisto drugačnega kulturnega okolja predstavljajo velik problem. Jaz recimo vem, da ko sva midva z mojim možem delala takrat izpit - to sva midve preverjali zadnjič - je on znal, on zna slovensko bolje kot jaz, tudi govori slovensko bolje kot jaz. Jaz imam ta balkanski naglas, ki se mu [smeh] iz nekaterih svojih osebnih razlogov nočem odreči. On govori zelo dobro, ampak je bil ocenjen slabše kot jaz. On je očitno imel neko tremo, ki je jaz očitno nisem imela. Definitivno ni nujno, da izpit pokaže realno stanje. Mogoče bi tudi preverjanja lahko zasnovali kako drugače, če bi že želeli oceniti neko realno stanje.

Še nekaj sem hotela reči, glede kulturnih razlik. Jaz imam zdaj sodelavca iz Sirije, ki dela z nami na Mirovnem inštitutu, ki smo ga zaposlili kot kulturnega mediatorja. On stalno izpostavlja te kulturne razlike, v smislu, kako imamo neke druge prioritete $\mathrm{v}$ zahodnem svetu. Recimo glede zamujanja, glede nekih natančnosti. Jaz bom stalno izpostavljala, da ne sme zamujati, da ko smo zmenjeni, da mora priti pravočasno. In on pravi: »Ne vem, ne razumem sploh tega koncepta. Pomembno je, da se mi imamo dobro [smeh], da se jaz spočijem, in če zamudim, to ni tak problem. « To so zanimive stvari, ko se soočaš $s$ takimi totalno različnimi svetovi.

Bi pa povedala glede kontinuitete, da je Slovenija migracijsko strategijo sprejela šele letos. Ker je integracija samo en del, eden od šestih delov. Tako da ... 
Igor Cetina: Neki dokumenti so že iz leta 2008.

Lana Zdravković: Dokumenti so, nek celovit dokument glede integracije pa je sprejet letos.

Igor Cetina: Hotel bi samo eno stvar povedati. Ko smo prej govorili o izobraževanju in o testih in tako naprej. Jaz bi tukaj poudaril, da so naši programi vsi mišljeni za starejše od 15 let. 15 let je meja za obvezno osnovno šolo v Sloveniji. Dosti je vezano tudi na specifiko andragoškega izobraževanja. Pogosto gre za slabše izobražene ljudi. Slabše izobražene - zdaj ne govorim o neizobraženih. Oni imajo srednjo šolo, poklicno šolo ali pa kaj takega. Zadnjič so se šolali leta ali pa desetletja, preden so prišli sem, tako da se morajo v okviru teh 180 ur, ki jih imajo na voljo, še enkrat začeti naučiti učiti. Pogosto je, glede na to, da so tako učitelji kot tudi mi, osredotočeni na vsebino, zelo velik izziv. Po mojem se to tudi pozna pri preverjanju, ker imajo tudi malo strahospoštovanja do avtoritete.

Ina Ferbežar: Še nekaj, če vas lahko dopolnim. Ja, to je res, mi opažamo, sploh pri malo nižje izobraženih, pri zdravnikih to ni problem, ker točno vedo, da gre za dva popolnoma drugačna jezika. Zaradi zgodovinskih okoliščin, o katerih je Marko $^{8}$ že prej pripovedoval na svojem plenarnem predavanju in Petra $^{9}$ je malo omenjala. Vajeni smo bili, da se nekako razumemo v isti državi, zdaj pa ni več tako. Dostikrat se tudi zgodi, da se ljudje, ko pridejo na izpit, niti ne zavedajo, da ne govorijo zares slovensko, ker v resnici oni ne govorijo več niti svojega jezika. Ampak se pač ne zavedajo, niti dostikrat nimajo dostopa do informacij. Ne vejo, da bi se pravzaprav lahko učili. Tukaj se mi zdi, da je potem tudi vprašanje motivacije. Dostikrat je, seveda, izgovor: »Tukaj sem zaradi dela.« Osebno velikokrat slišim: »Tukaj sem zaradi dela, ne zato, da bom hodil v šolo. « Zato tudi več hodijo ženske. To je pač dejstvo, s katerim se mi dnevno soočamo tudi na Centru za slovenščino. Samo to sem hotela dopolniti. Kar izvolite.

Igor Cetina: Še eno stvar bi dodal. Če govorimo o južnoslovanskih govorcih, predvsem s področja bivše Jugoslavije. To so edine skupine v Sloveniji,

8 Marko Stabej, ki je na posvetu sodeloval s prispevkom Sojezičje: utopija ali realnost?.

9 Petra Likar Stanovnik, ki je na posvetu sodelovala s prispevkom Kako predsodki vplivajo na ocenjevanje (na primeru slovenščine). 
za katere lahko trdimo, da imajo tukaj neko skupnost, bolj ali manj trajno. Pogosto je tukaj že druga, tretja generacija. Številni med njimi ne vedo, da ne govorijo slovensko, tudi zaradi tega, ker se jih preprosto razume. Njihovi otroci, njihovi vnuki, ljudje, ki so doma odraščali ob južnoslovanskih jezikih, zdaj delajo v trgovini, delajo na pošti, delajo v uradih. Pogosto lahko s svojo mešanico opravijo praktično večino zadev. Ne morejo pa preiti preko formalnega preverjanja znanja.

Lana Zdravković: Jaz sem se hotela navezati. Hotela sem izpostaviti, kakšna je percepcija osebe, ki ne govori dobro slovensko glede na poreklo te osebe. Če imamo osebo z zahoda, visoko izobraženo, belo, ki govori recimo angleško, francosko, to ni tak problem. Jaz poznam tudi ljudi, umetnike ali pa visoko izobražene ljudi, znanstvenike, ki tukaj delajo in sploh ne govorijo slovensko, ki so tukaj po deset let in funkcionirajo na ravni angleščine. To ni tak problem, ker to so kulturni, fini, izobraženi ljudje. Potem pa imamo te, ki prihajajo s tako imenovanega globalnega juga, ki so pa »umazani «, to so begunci, to so tujci, ki so rangirani drugače. Jih nočemo, ker prihajajo sem »vzet naše ženske, naše službe«. Percepcija je čisto drugačna. Jaz temu rečem sindrom »Kako dobro govorite slovensko«. Ko sem se jaz preselila sem in smo se pogovarjali s prijatelji in znanci, sem jaz vedno to doživljala kot eno kulturno klofuto: »O, kako dobro govorite slovensko, glede na to, da niste od tukaj.« To se na ta način začne. Če mi slišimo nekoga govoriti albansko ali pa makedonsko ali pa arabsko ... Jaz sem se enkrat z enim Albancem pogovarjala. Je rekel: »Mi govorimo naš jezik, pa vidim, da je arabski jezik podoben. Mi, ko govorimo, vedno izgleda, da se kregamo med sabo [smeh]. Malo agresivno vse to skupaj izgleda. « Ko mi potem to slišimo na ulici, je to čisto neka druga percepcija te osebe, tega tujca, kot pa percepcija tujca, ki prihaja z zahoda in govori lepo francosko ali pa italijansko in nam je to vse tako malo romantično. Tega se je tudi treba zavedati: kako percipiramo ljudi s tako imenovanega globalnega juga in z »razvitega zahoda«. Tudi osebe, ki prihajajo iz višjih razredov, ki so izobražene, in tiste, ki so pač gola človeška bitja in nimajo nič drugega razen tega, da so pač ljudje.

Ina Ferbežar: Hvala lepa. Težko temo smo odprli. Se bomo še vrnili. Tukaj smo imeli tri govorce, kjer smo se koncentrirali na enojezičnost, kjer je v središču slovenščina, izpiti so iz slovenščine, so enojezični. Zdaj bi pa prešli 
malo drugam. Mi živimo v večjezični realnosti. To je bilo danes že velikokrat izrečeno. Smo raznojezični, smo plurilingvalni. To je pač realnost. Nekateri delodajalci živijo tako resničnost. Na primer gospa Zupančič, ki prihaja iz podjetja Revoz, ki je eden večjih zaposlovalcev v Sloveniji. Nekih, ste rekli, tri, štiri tisoč ljudi je zaposlenih pri vas. To podjetje živi večjezičnost in raznojezičnost. Ali lahko predstavite, kako to izgleda v praksi v vašem podjetju, koliko jezikov imate, a ste jih kdaj prešteli v vašem podjetju? Prosim.

Tina Zupančič: Seveda imamo veliko, veliko jezikov, ker smo mednarodno podjetje. Sodelujemo tudi z ostalimi tovarnami, ker smo le ena izmed štiridesetih Renaultovih tovarn po svetu. $\mathrm{V}$ tovarni to izgleda tako, da večinoma seveda govorimo slovensko. Je pa zelo prisotna tudi francoščina, včasih je bila veliko bolj. Zadnje čase opažamo, da postaja čedalje bolj prisotna tudi angleščina, predvsem na sestankih. Ogromno sestankov imamo z drugimi tovarnami po Skypu in tukaj je francoščino že zamenjala angleščina. Je pa tako: ko imamo projekt, pridejo na srečanje inženirjev sodelavci iz Romunije, naš direktor je Turek, ki govori tekoče angleško, francosko, slovensko se trudi s posameznimi besedami, si zapisuje zanimive izraze. Mi smo veseli, seveda. Tujcem, ki pridejo v tovarno, ponudimo možnost učenja slovenščine. To se mi zdi zelo pomembno. Vsi ti sodelavci pravijo, da mogoče ne toliko zaradi življenja v tovarni in komuniciranja s sodelavci, predvsem da se lažje vključujejo v družbo, v okolje. To bi bilo mogoče za začetek.

Ina Ferbežar: Ko sva se pogovarjali, ste omenili, da imate vi neko prakso, da imate različne napise $\mathrm{v}$ različnih jezikih $\mathrm{v}$ menzi, povsod.

Tina Zupančič: Ja.

Ina Ferbežar: Kako to funkcionira?

Tina Zupančič: Menije imamo recimo v slovenščini, angleščini, francoščini. Imamo tudi službo za prevajanje, ki pomaga pri jezikovnih zaprekah. Ko imamo recimo izobraževanja v angleščini, se s službo za prevajanje dogovorimo, da pridejo prevajat v slovenščino. Potem napisi, če pogledamo računalnik, imamo Renaultovo računalniško okolje, kjer imamo možnost izbire vseh jezikov, ki jih ponuja Renault Renaultovim tovarnam. Zdaj so nam povezali katalog izobraževanj, tako da si lahko nastaviš jezik in izbereš katalog izobraževanj v svojem jeziku. To se mi zdi tudi v redu. Sámo izobraževanje je 
potem v slovenščini. Ravno zaradi tega tudi spodbujamo učenje slovenščine. Varstvo pri delu na primer ponudimo v jeziku tega sodelavca, ampak naprej pa vidijo, da se morajo tudi oni naučiti slovensko, da se je za lažje vključevanje v skupnost in okolje dobro naučiti slovensko.

Ina Ferbežar: Se pravi, vi jim organizirate tudi tečaje slovenščine? Tina Zupančič: Tudi.

Ina Ferbežar: Kako motivirani pa so? Koliko časa vztrajajo? Ker dostikrat je pri teh tečajih tako, da pridejo, potem pa če ni ravno obvezno ... Ne tako kot recimo pri ZIP-ih, kjer imajo vendarle neko boniteto in vsaj na izpit grejo lahko zastonj. Koliko časa potem ...?

Tina Zupančič: To je pa čisto odvisno. Kar se tiče tečajev slovenščine, smo nekako razdelili tečaje slovenščine glede na materni jezik sodelavcev. Pred dvema letoma smo se soočili s situacijo pomanjkanja delovne sile in je k nam prišlo veliko sodelavcev iz Bosne, iz Hrvaške. Takrat smo bili v nekem trenutku soočeni s situacijo, da je bilo potrebno organizirati tečaje slovenščine. Ponuditi smo jim želeli možnost teh tečajev in so jih opravljali pred službo, nismo jih mogli ponuditi znotraj delovnega časa. Jaz se trudim, da bi bilo med delovnim časom, če se le da. Tako imamo francoščino, nekaj slovenščine je tudi med delovnim časom, ampak za spremljevalne službe. To so bili pa delavci večinoma iz proizvodnje in je bilo moteče za proizvodni proces. Ne bi bilo možno izpeljati, da bi bilo med delovnim časom, in smo jih povabili izven delovnega časa. Je pa res, da je bilo na začetku navdušenje veliko, na koncu pa so večinoma ostale ženske. [smeh] Tako kot je bilo povedano. Je pa glavna motivacija za učenje, se mi zdi, za osnovni nivo, namenjen za nižja delovna mesta, kjer ni obvezno znanje slovenščine. Je pa obvezno, čim grejo na višja delovna mesta, kjer imajo več komunikacije z ostalimi sodelavci, tudi strokovne, tem delavcem smo pa kar v program poleg vseh izobraževanj dali tudi slovenski jezik.

Ina Ferbežar: Na izpit jim pa ni treba?

Tina Zupančič: Imajo ob koncu tečaja izpit. Ni pa, da bi bilo to na uradni ravni. Ker tudi pri drugih jezikih - angleščini, francoščini - ne zahtevamo tega. 
Ina Ferbežar: Vi vidite pravzaprav dodano vrednost v tej svoji večjezičnosti. Ali bi imeli kakšne smernice za kakšna podjetja, recimo v turizmu? Tam zlepa ne vidimo, da bi se učili slovenščine. Mi dobivamo informacije, da morajo turistični delavci delati izpit na A1, ki pa trenutno še ne eksistira v Sloveniji. Ali imate kakšen nasvet?

Tina Zupančič: Mi, kar smo naredili, smo se povezali v okolju in izkoristili razne programe, ki jih ponuja ministrstvo, tudi z jezikovnimi šolami smo sodelovali. Predvsem se mi zdi, da mora biti vsebinsko usmerjeno, ne pa v celoti. To potem lahko delaš na višjem nivoju, osnove pa morajo biti. Se mi zdi, da neko osnovno, splošno sporazumevanje mora biti, potem pa lahko greš na strokovni nivo.

Meni je bila zelo všeč naslednja ideja: ko je pred nekaj leti prišel novi vodja, je rekel, da so njemu ponudili učenje slovenščine še pred nastopom funkcije v Sloveniji. Z ženo sta šla na tečaj zato, da so ju pripravili. Mi smo potem samo nadgradili njegovo znanje. Tudi nekateri Francozi, ki pridejo v Slovenijo, imajo že v pogodbi napisano: tečaj slovenščine v Sloveniji. Imajo 60-urni tečaj, jaz ga organiziram in so zelo zadovoljni. Je pa učenje jezika dolgotrajen proces. Ne moremo pričakovati, da se bojo v enem letu, oziroma če pridejo na misijo za tri leta, da se bojo naučili v treh letih tekoče govoriti slovensko. Je pa res so mi sami povedali - da jim zelo pomaga, ko gre vodja med delavce, da lahko tudi on od njih iz prve roke izve, da ne rabijo imeti vedno prevajalke, da se ne rabi angleščine posluževati, ker tudi vsi francosko ne govorimo.

Ina Ferbežar: Se pravi, ta čisto človeška komunikacija.

Tina Zupančič: Ja, čisto zaradi tega. Tudi da mogoče pride do realnih informacij. Tudi to je mogoče en faktor. Tako da zelo spodbujamo tudi učenje slovenščine.

Ina Ferbežar: Hvala lepa. Zdaj pa pričakujem mogoče en tak bolj splošen pogled. Pa bom profesorja Stabeja prosila. Danes smo že dvakrat slišali, da je za Slovence slovenski jezik že celo zgodovino zelo močno identifikacijsko sredstvo, nekako temelj narodnega obstoja, da se to odraža v zelo osebnem, zelo čustvenem razmerju do slovenščine. To je tudi že gospa Zdravković omenjala. Glede na vse tole povedano, kaj bi rekli, kakšne jezikovne ideologije usmerjajo trenutno jezikovno politiko v Sloveniji? Kako krmariti med to čustvenostjo na 
eni strani in med takole realnostjo, ki jo imamo na drugi, kjer je samoumevno, da je več jezikov, da govorimo različne jezike? Kako loviti, kako držati to ravnovesje? Da ne bojo, ne bomo prizadeti tisti, ki smo zelo čustveni, pa tudi tisti ne, ki racionalno grejo $\mathrm{v}$ to?

Marko Stabej: Hvala. Jaz sem zelo vesel, da smem tole poslušati, in sem vesel tega, kar je bilo tukaj izrečeno. Na tako zgoščen način tako rekoč tako različnih glasov na to temo že zlepa nismo slišali. Jaz niti ne bi o čustvenosti sami po sebi govoril. Sem pa že prej omenil: čustvena reakcija je pogosto povezana z iskrenimi procesi, pogosto pa z nevednostjo. Meni se zdi, da so tukaj sami primeri, kako je edina rešitev po eni strani humanističen odnos do vsega skupaj, po drugi strani pa pragmatično reševanje težav, ne bom rekel težav, ampak ovir za skupni cilj. Pri tem je treba čustva po mojem seveda pustiti na neki način, naj živijo, ampak ne kot glavni argument česarkoli. Moja izkušnja skupaj s tvojo, saj sodelujeva že dolgo časa in tudi z nekaterimi med vami, je, da stvari gredo postopno. Izkaže se, da je za nekoga 180 ur premalo, to že vemo, da je 320 ur premalo. Ampak še pred desetimi leti se je zdelo 50 ur za vsakogar preveč oziroma odveč. Pričakovanje, da se ozaveščenost vseh lahko spremeni tako »on/off, pak, pa smo ozaveščeni«, je irealno. Važno pa je, zato se mi tudi današnji dogodek zdi razmeroma važen (ne vem, če je, ampak je dragocen), da slišiš različne glasove. In ob neki dobronamernosti lahko najdeš rešitve, ki jih prej ni bilo.

Če smem kolega Ihana rahlo parafrazirati. Če smo za migracijo zdravnikov in večjo potrebo med drugim odgovorni tudi vse zahtevnejši pacienti ali pa vse bolj razvajeni pacienti, na nek način enako velja za udeležence izobraževalnih procesov, pa tudi migracij. In je prav tako. Hkrati je pa sistem marsikdaj narejen - spet se opravičujem - po analogiji, tako kot je bila medicina včasih predvsem, da zdravi in ne preprečuje. Če imaš vse sisteme narejene predvsem za zdravljenje, najbrž stežka kakšen preventivni program zaženeš. V Sloveniji sta vsaj dva taka, ki sta zelo uspešna. Eden je Dora za raka na prsih, presejalni, drugo je Svit za ...

Alojz Ihan: Za raka črevesja.

Marko Stabej: ... za raka črevesja. Jaz si predstavljam, da ti sistemi zelo veliko stanejo, ampak najbrž konec koncev mnogo manj, kot bi bilo dolgotrajno zdravljenje marsikoga, ki na teh testih ne bi pravočasno odreagiral. 
Pri jeziku smo daleč od takih presejalnih testov zato, ker se nam je dolgo časa zdelo samoumevno, da kdor pride, če hoče, naj se že nauči. Če se noče naučiti, je sam kriv. Najbolje pa, da ne hodimo nikamor in da smo tukaj mi, drugi pa naj bodo drugje. Vsi se tega šele navajamo in redko sedimo skupaj. Tak primer, kot je bil predlog kolega Ihana, neko vmesno leto zdravnika, ki pride, da že dela in se lahko sproti uči. Analogija je tudi na univerzi, vsaj v Ljubljani. Po dolgih letih spraševanja, kako poservisirati ljudi, ki pridejo sem študirat in morajo študirati vsaj večino programa v slovenščini, na kakšen način jih naučiti slovensko. Nerealno je, da jih boš v enem mesecu naučil, čeprav so to inteligentni mladi ljudje, da jih boš naučil na ta način, da ga potem vržeš v seminar ali kamorkoli. Prišlo je spoznanje, da je treba organizirati neko posebno obliko, ki je do takrat ni bilo. Imenuje se Leto plus, kjer lahko deloma študirajo, deloma pa so obvezani, da se učijo slovenščino in se jim ne šteje v siceršnji rok študija, se pravi neka dodatna pravica. In so se začele stvari v zadnjih dveh letih bliskovito urejati. Seveda pa imamo vsi zaradi tega organizacijske, kadrovske, konceptualne težave. Ampak mi smo tukaj zato, da se s temi težavami soočimo in jih rešujemo. Marsikdo, zlasti ki je zunaj realnih okolij, pa misli, da se ukvarja z usmerjanjem jezika in jezikovne situacije, pa strelja kot najslabši kavboj v najslabšem filmu. On bi vse takoj. Ali bom jaz zmagal ali bo kdo drug zmagal, če lahko tako. V tem smislu je teh refleksov še preveč, hkrati so pa ta vprašanja marginalna, čeprav gre za vprašanja življenja in smrti, sprejetosti, nesprejetosti. Tukaj se mi zdi, da smo zelo napredovali, zlasti ker ljudje konkretno začnejo razmišljati. Dober primer, se mi zdi, je Revoz. Na koncu koncev vaša firma mora profitirati. To ne pomeni, kot marsikdo, ki ima stereotipne predstave, ki je bolj domač ljubitelj slovenščine in njenega statusa, misli in je prepričan, da vsi, ki hočejo zaslužiti, itak vse samo v angleščini počnejo. Kdor resno služi, ve, da je to bistveno kompleksnejša zadeva. Ne vem, če sem odgovoril, kako s tem ravnati. Treba je imeti forme, da si poveš. Treba je imeti self-assessment, da sam pri sebi znaš razmišljati, kaj bi pa lahko naredil, da bi bilo boljše, kaj je zdaj realno, kaj ni realno, kaj bo realno. Kdaj bom zaprosil za nek dodatni denar, pa ga bom čez tri ali pa pet let dobil. To šele nastaja.

Ina Ferbežar: Ja, hvala lepa. To se mi zdi zelo pomembno: kaj je realno. $\mathrm{S}$ tem smo se tudi zelo veliko $\mathrm{s}$ profesorjem Ihanom ubadali v naši delovni 
skupini, kjer pripravljamo ta izpit, o katerem je na začetku pripovedoval. Izpit, ki je zdaj na C1, za zdravnike sploh ni realen. Je pa tudi tako, da marsikateri zdravnik ima sam nerealna pričakovanja najprej do sebe, češ, saj se jaz lahko to hitro naučim, ker prihajajo večinoma iz sosednjih, bližnjih dežel, kjer se govori slovenščini sorodni jezik. Malo podcenijo slovenščino pa malo precenijo sebe. Se mi zdi ta rešitev res dobra. A se vam zdi, profesor Ihan, da bodo delodajalci pripravljeni dati čas in denar za to, kot deloma, vsaj deloma v Revozu počnejo? Se vam zdi to realno? Jaz imam malo zlo slutnjo, da se bo pri denarju zelo hitro ustavilo.

Alojz Ihan: Trenutno se mi ne zdi realno. [smeh]

Alojz Ihan: Realno je, da se ta proces začne v državnih bolnicah. Država ni tako zahteven lastnik, kar se tiče denarne racionalnosti, medtem ko pa ni realno, da bi to financirali delodajalci v privatnem sektorju. Ti upori so že bili in se je potrebno tem uporom izogniti in vzpostaviti sistem, na primer v zdravstvenih domovih, v državni mreži zdravstvenih domov.

Zdaj imamo že številne kraje, ki so brez zdravnika. Tam pa se morajo lokalne skupnosti odločiti. Primarno zdravstvo financirajo lokalne skupnosti. V Sloveniji država financira bolnice, medtem ko te splošne ambulante financirajo občine. Že zdaj se tam, kjer ni zdravnika, morajo občine odločiti, da če hočejo dobiti zdravnika, mu morajo ponuditi stanovanje. Če mu ne ponudijo stanovanja, ne bodo dobile zdravnika. Nek tak tečaj je malenkost v primeri s stanovanjem. Vzorec se da narediti, ampak da bi pa to postalo splošno obvezno, je pa vprašanje.

Ina Ferbežar: Bomo poskusili. Imamo še kar nekaj časa, ker smo zamudili 15 minut. Jaz bi predlagala, če bi imel kdorkoli iz publike kakšno vprašanje za moje goste. Kot ste videli, odpade naša popoldanska delavnica, ki naj bi nadaljevala tale pogovor. Če bi bila kakršnokoli vprašanja, jaz mislim, da bodo moji gosti čisto veseli. Če ne, imam pa jaz kar nekaj vprašanj še za njih za rezervo.

Ne? No, dobro.

Potem pa imam eno, pravzaprav za vse. Veliko se govori o tem, da je Slovenija prehodna država, da vse tendira proti severu. To je tudi profesor Ihan čisto na začetku rekel, da se vse seli proti severu. Mi dejansko v Izpitnem centru 
slišimo od naših kandidatov za izpite: »Ah, jaz to rabim samo zato, da bom dobil potni list, potem grem pa naprej.« Tudi od zdravnikov smo to že slišali. Se mi pa zdi, da zelo veliko ljudi ostaja, da nimajo kakšnih intenc hoditi daleč. Kakšna je vaša izkušnja, kakšno je vaše mnenje o tem? Smo zares prehodna država, ali smo vendarle ...? Lana, boš ti?

Lana Zdravković: Kakor za koga. Meni je zanimiva ena anekdota. Ko se je vzpostavila balkanska ruta in so začeli ljudje iz Sirije, Iraka, Afganistana hoditi čez Slovenijo, je bila glavna skrb nekaterih politikov, da Slovenija ne bi postala žep za migrante. To je pomenilo, da ne bi Avstrija zaprla meje in bi potem oni ostali tukaj. Potem je neka begunka iz enega izmed vlakov izjavila točno to: da nobeden izmed njih ne želi ostati v Sloveniji, da je njim vseeno cilj Nemčija, skandinavske države. Potem je slovenska javnost dobila napad: »Zakaj nočejo ostati? A mi pa nismo dobri?! « [smeh] To je bilo fenomenalno.

Meni se zdi, da so večini tem novim migrantom, ki zdaj prihajajo, cilj druge države. Razlogi so zelo enostavni. Eno je, da tam že imajo vzpostavljene neke socialne kontakte, prijatelje, družino ali kogarkoli že poznajo. To so države, ki imajo migrantsko preteklost že dolgo. Način vključevanja in integracije je vzpostavljen, tudi neformalni predvsem, in te povezave funkcionirajo. Seveda večina ljudi želi iti nekam, kjer je že slišala, da nekaj obstaja, da je nekdo že tam. To so seveda Nemčija, skandinavske države, Italija, Francija. Po drugi strani pa ljudje iz bivše Jugoslavije predvsem zaradi kulturnih povezav nekdanjega skupnega prostora Slovenijo doživljajo kot ciljno državo, velikokrat tudi zaradi skupne preteklosti. Imamo cel val preseljevanja iz republik nekdanje Jugoslavije v sedemdesetih letih prejšnjega stoletja, ekonomske migracije, ko se je začelo. Tudi iz teh razlogov tukaj že obstajajo neke skupnosti, ki so vzpostavljene. Če je za najnovejši val migrantov Slovenija predvsem prehodna država, je za tiste iz našega kulturnega prostora tudi ciljna država.

Bi pa povedala tudi to, da moj sodelavec iz Sirije, ki zdaj dela z nami na inštitutu, on je tudi bil vsepovsod. To so ta »razturena « življenja, ko si šest mesecev tukaj, pa te deportirajo, pa si malo v zaporu in greš nazaj, pa si malo v Italiji, malo v Franciji, malo ne vem kje. On je dobil status v Sloveniji, živi v Sloveniji. Povedal je, da se edino v Sloveniji počuti kot človeško bitje, da se nikjer, niti doma v Siriji, ni počutil tako. Zato je od tam tudi bežal, ker mu ni bilo dobro. Potem je bil vsepovsod v različnih postopkih. Rekel je: »Lana, ti imaš ful 
srečo. Dobro si se odločila, da si migrirala v Slovenijo. [smeh] Ker jaz se edino v Sloveniji počutim kot človek. « Meni je bilo to tako: »Mhm. « Ker se tudi jaz v Sloveniji počutim boljše kot pa drugje.

Ina Ferbežar: Take stvari si zelo želimo slišati. Še kdo mogoče? Publika?

Alojz Ihan: No, mogoče še o zdravnikih. Slovenija je za zdravnike enako prehodna država, kot je za slovenske zdravnike. Približno enak odstotek slovenskih zdravnikov si želi iti drugam, kot je odstotek tistih, ki pridejo v Slovenijo in si želijo iti drugam. To velja tudi za mlade. Moramo pa vedeti, da je tipična pot mladih zdravnikov na primer iz Srbije, Bosne v Slovenijo, da pridejo po dokončani medicinski fakulteti in v Sloveniji zaprosijo že za specializacijo. V Sloveniji je razpisanih veliko več specializacij, kot pa je mest na medicinskih fakultetah. Kar pomeni, da tisti, ki konča medicinsko fakulteto v Beogradu, potem naredi te nostrifikacijske dokumente, ki jih ni težko narediti, ker so fakultete primerljive. Potem naredi izpit. V Sloveniji potem začne s specializacijo, ki jo plača, seveda, in s katero lahko gre enako kot vsak Slovenec kamorkoli v evropski skupnosti. Ampak izšolati se za zdravnika v enem jeziku je tako velika investicija - ker v Sloveniji dobi zdravnik službo takoj, da si večina strok ne želi potem ponovno iti v to jezikovno investicijo v neko drugo okolje. Na koncu je pa treba s pacienti komunicirati. Če se naučiš komunicirati v slovenščini, potem ni enostavno iti v Nemčijo in se začeti učiti spet naslednjih tri, štiri, pet let in jih porabiti za to, da komuniciraš v nemščini. So pa določene stroke, kjer je to vseeno, recimo kirurgom je popolnoma vseeno, ali režejo v ...

Lana Zdravković: V slovenščini ali v arabščini. [smeh]

Alojz Ihan: ... ali režejo v arabščini ali v slovenščini. Tako da so nekatere stroke, kjer je migracija ogromna. Ampak to je isto pri nogometaših. [smeh]

Ina Ferbežar: Potem pa predlagam, da mogoče zaključimo pri nogometaših. Jaz bi se vsem res najlepše zahvalila, da ste prišli. Mislim, da je res dobro, to, kar je Marko rekel, še enkrat, da se takole srečujemo. Rada bi citirala našo drago profesorico, ki je bila moja mentorica pa tudi Markova mentorica, naša draga mentorica profesorica doktorica Breda Pogorelec, žal pokojna. Vesela bi bila tega dogodka, rekla bi, da je praznik. Njen citat je bil vedno: »O tem se bomo še pogovarjali.« Tako da najlepša hvala mojim gostom, najlepša 
Slovenščina 2.0, 2020 (1)

hvala vam, čeprav niste nič spraševali. Mogoče boste sedaj pri kosilu. Najlepša hvala mojima dragima tolmačema tamle zadaj, Jana Zidar Forte in Boštjan Zupančič. [aplavz]

Vas toplo vabim na prigrizek za kosilo. Izvolite. 